\title{
UK HIGHER EDUCATION LIBRARY STATISTICS
}

\author{
Claire Creaser, LISU, Loughborough University
}

\begin{abstract}
Academic libraries in the UK have a long history of collecting management statistics about their operations. This paper describes the role of the Society of College, National and University Libraries (SCONUL), and its predecessor bodies, in developing this data collection into the comprehensive database which exists today. Universities, polytechnics and colleges formerly each had their own library organisations, but as the sector itself has become more coherent, so SCONUL has evolved and grown to represent libraries in all types of higher education institution in the UK. All universities, and all but a handful of higher education colleges, are members, and over $80 \%$ submit their statistics annually. SCONUL member institutions educate $99 \%$ of the UK's publicly funded HE students.

The paper covers the development of the SCONUL statistical return and the processes by which the relevance of the data collected, and the management statistics provided in SCONUL's publications, are monitored and updated. SCONUL currently produces three annual publications, the Annual Library Statistics, UK Higher Education Library Management Statistics, and SCONUL Library Statistics: Trends. Each of these is described, and examples given of the outputs available and the overall purpose of these. SCONUL also makes available, to its members, a comprehensive statistical database which was initially developed in 2002 and is currently maintained by LISU. The rationale and methodology behind the development of this database is outlined, and current proposals for further enhancement described. Members can interrogate the database directly from the SCONUL web site, and a selection of examples of the main analyses available will be presented.

SCONUL data are used for a wide variety of purposes, by individual libraries, SCONUL as an organisation, and by researchers. A selection of the uses to which the data are put will be outlined, including the development of performance indicators, library evaluation programmes, a variety of benchmarking analyses for individual library services, and advocacy, both for individual libraries within their institution and at the national level.
\end{abstract}

\section{INTRODUCTION}

SCONUL is the UK umbrella organisation for academic libraries in the UK and Ireland. It was founded in 1950, as the Standing Conference of National and University Librarians, but did not begin to collect statistics about members' libraries 
until 1987. In April 1994, following a re-structuring of higher education provision, SCONUL merged with the Council of Polytechnic Librarians (COPOL); at that time it had 120 full members (universities and national libraries) and five associates (other higher education institutions) ${ }^{1}$. COPOL also had a history of collecting financial and management statistics from its members, and in 1995 LISU became involved with the compilation of the first combined volume of data.

In 2001, again following changes to the education system, SCONUL merged with the Higher Education Colleges Learning Resources Group (HCLRG). This group represented a very diverse set of colleges, and had already begun to collect statistics, using a subset of the SCONUL form. SCONUL was re-named the Society of College, National and University Libraries, to reflect its wider role, and began to collect and publish management statistics which encompass all UK universities, and all but a handful of HE colleges - approximately $85 \%$ of members submit their statistics each year. SCONUL member institutions now educate $99 \%$ of the UK's publicly funded HE students, and all UK HE institutions are invited to contribute key data, even if they are not members of SCONUL. Due to a difference in the timing of the academic year and using a different currency (Euro), members in the Republic of Ireland do not, currently, participate in the data collection exercise.

\section{DEVELOPMENT OF THE RETURN}

SCONUL statistics have been developed by librarians for librarians, with the aim of 'providing sound information on which policy decisions can be based'. ${ }^{2}$ As a result, they have evolved over time, both in terms of the activities which are included, and the definitions applied to the data. This development is overseen by the Working Group on Performance Improvement (WGPI); it has a Statistics subgroup which meets annually to consider the detail of the return, and what, if any, changes are appropriate. Wherever appropriate, the latest ISO definitions are used when introducing new data elements, although there is an element of pragmatism in terms of collecting data which are both useful and available.

In practical terms, the data collection process has evolved from one entirely based on a paper form, through electronic submission via Excel spreadsheets, to a flexible web-based form. The process is supported by the SCONUL office, which controls access to the return and the statistics, and chases late respondents each year. Hosting is provided by the University of Bristol, and LISU, based at Loughborough University, undertakes the analysis and preparation of the statistics:

1 Pentelow, Gillian, 1994, 'Standing Conference of National and University Libraries', Serials, 7(3) pp. 233-236

2 SCONUL web site, accessed 23-7-08 http://vamp.diglib.shrivenham.cranfield.ac.uk/statistics/sconulannual-library-statistics 


\section{Box 1 Areas covered by the 2006-07 SCONUL return}

Organisational structure

Accommodation

Library space, seating \& workstations

Provision of stock

Print \& electronic, stock \& acquisitions, disposals

Clientele

Use

Visits, circulation, ILL, enquiries, e-use

Staff numbers

Expenditure

Staff, information provision, equipment, other

- Monitoring \& checking returns;

- Compiling the data;

- Income

- Preparation of the main statistical reports;

- Maintaining the databases;

- Preparing the analysis of trends;

- Answering enquiries, both on the detailed form as well as about the figures themselves; and

- Preparing commissioned analyses.

The last major revision to the data collection was made more than ten years ago, when the detail collected on different stock formats, and much of the detailed breakdown required for financial data, was simplified. Since then, minor revisions have been made annually, most notably in the area of electronic resources, where the data collection has expanded in line with the increasing importance of this aspect of the academic library, and changed to keep up with changing technologies. Box 1 shows the areas covered by the current return; readers who wish to see more detail are referred to the demonstration form available on the SCONUL web site. ${ }^{3}$

A number of example pro-formas are provided to assist libraries in the collection of data relating to some areas of the return, in particular for the enquiry count and some elements of the financial data. 


\section{USING THE DATA}

In the early years of data collection, the SCONUL statistics were viewed with scepticism by a great many people, including some of those who provided the data. Even when they were convinced that their own data were reliable, and accurate, some respondents did not believe the same of all the other contributors, with some justification. Over time, the statistics have become much improved, and the quality has increased each year. The reasons for this are many, and include technological advances which provide system statistics at the press of a button; familiarity with the software; increased emphasis on the application of quantitative evidence within institutions; and increased use of the data both within and beyond the academic library community. Training sessions are also available for library staff compiling and using the data. The key evidence for this quality improvement is the inherent consistency of the data - library statistics do not, on the whole, change dramatically from year to year, and this is apparent in the majority of areas covered by the SCONUL statistics set. There are exceptions, and areas where less confidence can be placed in the figures, but these are well known, and treated with appropriate caution.

LISU maintains a database derived from the annual returns which goes back in part to 1991-92, although the figures for the earliest years are less complete. The majority of areas have reliable data which goes back for ten years or more, and this is an invaluable resource, as it means that the statistics can be used not only to demonstrate the current position, but also how that position was arrived at. This is available for internal management use by SCONUL members, for benchmarking at a variety of levels, and for advocacy at a local and national level. It is also possible to derive statistics which can be compared internationally.

\section{STATISTICS PRODUCTS}

Each year, LISU, working on behalf of SCONUL, produces five basic statistics products:

\section{SCONUL annual statistics}

This is the main product of the statistical return, and is the one which has been available for the longest time. It reproduces the data as submitted by each institution (after correction if necessary), including all the notes which accompany the figures. Institutions are presented in a single sequence, and summary figures are calculated for the four main UK sectors (Research Libraries UK members; other pre-1992 universities; post 1992 universities; and other HE institutions) and for the membership as a whole. Because of the diverse nature of HE libraries, selected distribution points are presented in addition to the arithmetic mean; these also al- 
low institutions to see at a glance where they fit in relation to others in their sector, without providing a formal ranking of libraries.

A substantial section of the report is concerned with an extensive set of ratios and derived statistics, which can be used to monitor performance and make comparisons with other institutions. Most performance indicators are calculated on the basis of full time equivalent (FTE) students, although some use an estimate of all FTE users, and others are proportions or other ratios. The derived statistics cover library provision and use, stock provision, expenditure and use, interlibrary activity, enquiries and staff workload, efficiency measures, expenditure and electronic resources.

A brief commentary is also included, highlighting key results and making some comparisons to the previous year. This report is available in print, and to contributors on the SCONUL web site. ${ }^{4}$

\section{Higher Education Library Management Statistics}

Known as HELMS, this report has been produced since 2001 as a supplement to the Annual Library Statistics. It comprises a small set of key management statistics and contextual data, and is designed for senior institution managers. Library data from SCONUL returns are supplemented with institution-wide data from the Higher Education Statistics Agency (HESA). Box 2 lists the statistics included. The format is rather different from the annual statistics, with institutions listed by country, and totals provided for each country and the UK as a whole. Another important difference is the use of FTE user as the divisor for ratios, in this case defined as FTE students plus academic staff, in line with other HESA reports. A short commentary and graphical presentation of the ratios is included, and relevant notes are reproduced. The report is currently only available in print format. ${ }^{5}$

\section{SCONUL database}

Each year, when the two annual reports described above have been completed, LISU staff undertake an extensive programme of careful checking and editing of the data in relation to previous years, to incorporate it into the SCONUL database. The object of this is to produce figures which are as complete as possible, and which conform as closely as possible to the original definitions, so that comparisons can be made between years and between institutions, with confidence. Each institution is considered separately, using all available information to correct for data which do not conform to the standard definitions, or to make estimates for key figures which are not available. Previous figures are checked for consistency, and any apparent discrepancies checked with the institution concerned; the reasonableness of previous estimates is also examined, and adjustments made if necessary.

SCONUL, 2008, Annual Library Statistics 2006-07, London, SCONUL

5 SCONUL, 2008, UK Higher Education Library Management Statistics 2006-07, London, SCONUL (in press) 


\section{Box 2 Management statistics included in HELMS}

SCONUL library management statistics:

Total library expenditure per FTE user

Expenditure on information provision per FTE user

Expenditure on library staffing per FTE user

Study place hours per week per FTE user

Loans per FTE user

IL as percentage of all loans

SCONUL library contextual data:

Number of libraries

Space occupied

Size of collection

Number of study places available

Number of workstations

Total library expenditure

HESA institutional contextual data:

Number of students

$\%$ of postgraduate students

$\%$ of part time students

Number of academic and research staff

Expenditure on total academic serv ices

Proportion of funding council funding for research

Note that, while all fields are edited with respect to conformity with the definitions, not all fields are edited for completeness; however all major expenditure heads, together with staff numbers, extent of collections, use of print collections, and space provision are covered routinely. Retrospective editing is carried out when specific requests are made, provided that there is a sufficient body of data on which to base reliable estimates. 
The SCONUL database covers 1991-92 to 2006-07. It includes figures in respect of all SCONUL members starting in the year in which they joined SCONUL if this was after 1991-92, or the year in which they first completed a data return, if earlier. No estimates are included for institutions which are not members of SCONUL and have never made a SCONUL return; however this is now less than 10 institutions, representing only $1 \%$ of the UK's publically funded higher education students. The aim is to have as complete and accurate a record as possible of HE library statistics in the UK. The database is not made publically available, but is used to prepare a generic trends report for members, and an edited version is available on the SCONUL web site for members to carry out their own analyses. Institutions may also commission analyses from LISU.

\section{Trend analysis}

The SCONUL trend analysis is prepared by LISU from the edited database of statistics. A ten year trend analysis gives summary figures on 15 key performance measures for each of the four sectors noted above, and for SCONUL members as a whole. There is an extensive commentary, and the data tables are illustrated graphically. Five broad areas are covered - contextual data, service provision, library use, staff, and financial data. The purpose of this analysis is to give an overview of performance in the sector, and to provide some broad figures against which individual members can benchmark their own results. The report is currently available to members only. Figure 1 shows an example page from the 2007 report.

\section{Statistics on the web}

The SCONUL Statistics on the Web database is derived from the full database held by LISU. It differs in the key respect that estimates are suppressed where an institution has not provided data for five years consecutively. While such estimates are valuable in the context of contributing to sector-wide totals to give consistency of trends, as records of individual institutional performance they may be significantly different from the true position, and so of little value for such detailed benchmarking applications. As well as data for individual institutions, the Statistics on the Web database is pre-loaded with summary figures for the four sectors described above, and the total for all SCONUL members. These totals include estimates for the omitted institutions.

A variety of analyses can be carried out, and some examples are illustrated below. Data for selected indicators and selected institutions can be listed (Figure 2). Ranked lists of all institutions on a given measure or ratio can be produced (Figure 3). Time series can be constructed comparing institutions across a single indicator (Figure 4), or comparing a selection of indicators for a single institution. Data can also be downloaded for export into a spreadsheet or other analysis software.

The database has been available to members for three years, and suggestions are frequently made for enhancements to the functionality. Current proposals being 
considered include changing the format of the graphs to make these more userfriendly, particularly for reporting purposes; and adding a new report which will allow the setting up of individualised groups of institutions for which totals and averages could be analysed and compared.

\section{OTHER USES}

The statistical products described above have a wide range of uses, for individual institutions, for the academic library sector as a whole, and for all those with an interest in the sector, including service suppliers, consultants, and researchers. Some examples of these are described below.

\section{Service evaluation}

SCONUL statistics are widely used by individual libraries for routine service evaluation. This can take the form of monitoring overall trends, for example to identify areas of service growth and decline, as well as managing stock, staff and services. Many institutions find the statistics essential for their internal planning and decision-making on a day-to-day basis. Note that for institutions with multiple service points, collection of standard statistics such as those required by SCONUL can also provide evidence for evaluation and benchmarking of individual service points as well as for the library service as a whole.

\section{Benchmarking}

This is one of the key uses of the SCONUL dataset, both by individual institutions using the web database, and commissioned from LISU. Ten years and more of reliable data allow trends to be examined, both in individual institutions and against averages. This gives context to the snapshot figures for the latest year, and indicates whether current performance is typical of recent years or not. The individual figures can be used to inform the objective selection of comparator institutions, using statistical methods such as nearest neighbour analysis, and to provide background and contextual data for more detailed process benchmarking exercises.

Selection of comparator institutions is key to successful benchmarking. In some instances these may be pre-determined, for example a key set of competitors might be used for comparison purposes across the institution. Alternatively, comparators can be selected with a particular aim in mind - for example as a set of institutions to which the library aspires. However, any set of comparators must be justifiable if the results of the benchmarking exercise are to be taken seriously, and followed by actions to change the service. The data set can be used to identify instances of potential 'best practice', with the historical data showing whether this is a consistent pattern or a one-off occurrence. Analyses may also demonstrate that particular institutions are not necessarily good comparators to use, for any number of reasons. 
Fig 29 Percentage of information provision expenditure on serials

\begin{tabular}{lrrrrrrrrrrr} 
& $95-6$ & $96-7$ & $97-8$ & $98-9$ & $99-0$ & $00-1$ & $01-2$ & $02-3$ & $03-4$ & $04-5$ & $05-6$ \\
\hline CURL & 56 & 53 & 49 & 52 & 51 & 53 & 54 & 59 & 60 & 60 & 56 \\
Other Old & 55 & 50 & 49 & 51 & 52 & 55 & 56 & 56 & 57 & 57 & 57 \\
New & 43 & 38 & 38 & 38 & 40 & 43 & 45 & 45 & 43 & 42 & 43 \\
HE colleges & 34 & 34 & 33 & 30 & 34 & 38 & 37 & 37 & 36 & 35 & 41 \\
\hline All members & 50 & 46 & 45 & 46 & 47 & 50 & 51 & 53 & 53 & 52 & 52 \\
\hline
\end{tabular}

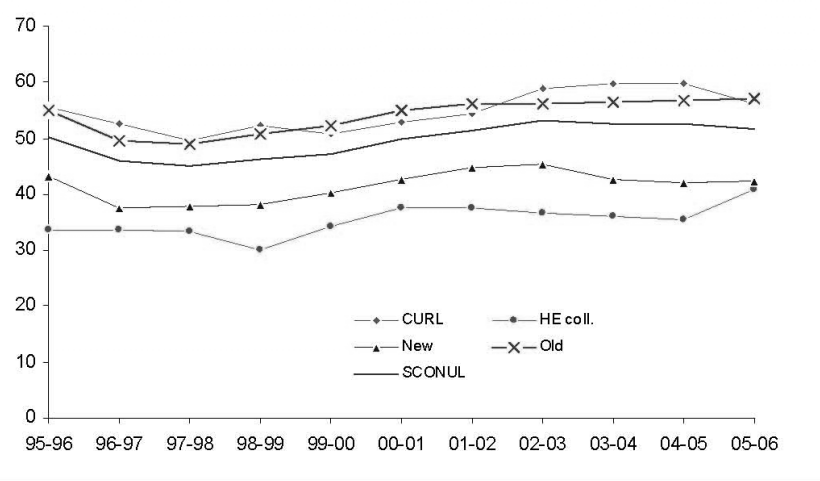

In contrast to the picture for books, the proportion of information provision expenditure on serials has remained unchanged, or increased in all sectors over the last five and ten years. The changing methods of delivery, with increasing emphasis on electronic serials, and the various charging models applied, render this area a particularly complex one. SCONUL collects data on serials expenditure by format, although the detail available is far from complete. Fig 30 illustrates the breakdown of expenditure since 2000-01. It is interesting to compare this with Fig 12, showing the breakdown of titles.

\section{Fig 30 Breakdown of serial expenditure by format}

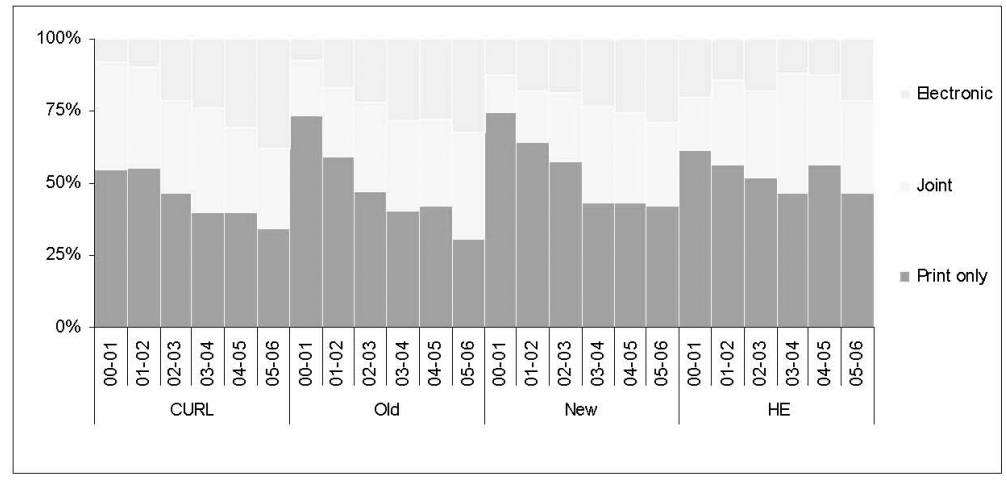

Figure 1 SCONUL trends analysis example page 
Database of Academic Library Statistics

( ccreaser )

$\triangle$ Return to Questionnaire Guidance

Institutional Data for 2005-06

\begin{tabular}{|l|r|r|r|r|r|r|}
\hline \multicolumn{1}{|c|}{ Variable } & Cambridge & Cardiff & Leeds & $\begin{array}{c}\text { University } \\
\text { of the } \\
\text { Arts }\end{array}$ & Manchester & Oxford \\
\hline No. of Libraries & 114 & 25 & 17 & 17 & 20 & 35 \\
\hline Library floor area & 64505 & 20755 & 27150 & 6486 & 42150 & 63594 \\
\hline Total study places & 7190 & 3221 & 3983 & 1181 & 3998 & 3892 \\
\hline
\end{tabular}

Figure 2 SCONUL statistics on the web - sample institutional data

\section{Database of Academic Library Statistics}

( ccreaser)

- Return to Questionnaire Guidance

Ranked Data for 2005-06

\begin{tabular}{|c|l|r|}
\hline Rank & \multicolumn{1}{|c|}{ Institution } & No. of Libraries \\
\hline 1 & All SCONUL members & 940 \\
\hline 2 & CURL members & 482 \\
\hline 3 & Post-92 Universities & 231 \\
\hline 4 & Other pre-92 Universities & 137 \\
\hline 5 & Cambridge & 114 \\
\hline 6 & Oxford - Coll. libraries & 113 \\
\hline 7 & All HE Colleges & 81 \\
\hline 8 & Oxford & 35 \\
\hline 9 & Cardiff & 25 \\
\hline 10 & Manchester & 20 \\
\hline 11 & Leeds & 17 \\
\hline 11 & University of the Arts & 17 \\
\hline 12 & UCL & 16 \\
\hline 13 & Bristol & 14 \\
\hline 13 & Edinburgh & 14 \\
\hline 14 & Imperial & 13 \\
\hline 14 & Liverpool & 13 \\
\hline 15 & Birmingham & 12 \\
\hline 15 & Nottingham & 12 \\
\hline & & \\
\hline
\end{tabular}

Figure 3 SCONUL statistics on the web - Ranked lists 


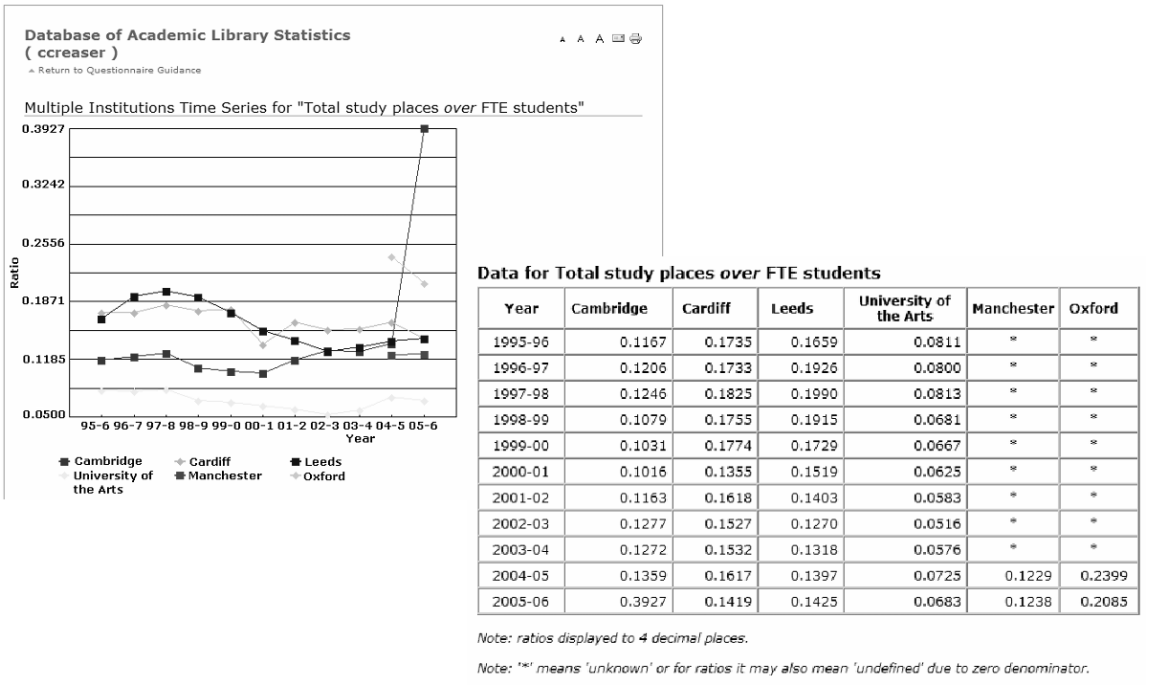

Figure 4 SCONUL statistics on the web - Time series

Note: Early data for Manchester and Oxford are shown as 'unknown' due to institutional and library mergers rendering these figures incomparable to the most recent data.

When benchmarking, it is important to compare like with like, and the editing process carried out on the SCONUL statistics database facilitates this to a large extent. While every academic library is different from every other academic library, having a set of data on consistent, well understood, definitions is an essential precursor to useful analysis. LISU also recommends carrying out statistical benchmarking procedures against averages of groups of institutions - usually around six for a specific comparison group - as this evens out any unusual figures in a single institution's data which might obscure the broader picture. Statistical benchmarking in this way is facilitated by the public availability of a comprehensive data set covering all aspects of library operations, albeit at a macro level.

\section{Advocacy}

Advocacy is a key role for the SCONUL statistics. Within institutions, this can be framed (according to the audience and purpose) to show how well a library service is performing, in comparison to previous history or to other institutions. This gives good publicity to the service, and is invaluable for marketing purposes. Properly chosen statistics can be used to demonstrate value for money, and efficiency of operation to the service stakeholders - staff, institutional management and users. On the other hand, statistics are also required to support business cases for additional funding or other resources, and here it is key to make valid comparisons, or the whole case will fail. 
Nationally, the broad statistics are used by the SCONUL office to inform government about the sector, both generally and in response to specific requests for information and evidence. They also underpin sector-wide negotiations, for example concerning licensing agreements.

A third group of users of the wider statistics is perhaps the most diverse, comprising those who provide services to academic libraries, such as publishers, consultants, library suppliers, equipment manufacturers etc. These users have need of data to inform their strategic planning to enable them to best meet the needs of academic libraries, and it is in everyone's interest to see that they have accurate information about the sector as a whole.

\section{CONCLUSION}

SCONUL has been collecting and publishing statistics from university libraries since 1987, with the aim of providing sound information on which policy decisions can be based. Carrying out a sector-wide data collection exercise on a voluntary basis requires commitment from the umbrella organisation as well as the individual libraries supplying data. It has taken many years for the SCONUL statistics to have reached the position they are in today, with the broad coverage and reliable methods which mean they can be - and are - used with confidence both within the sector and beyond it. SCONUL's web site neatly sums up the current position:

'SCONUL's statistics are hard work to produce and they are worked hard once they are published.'

The statistics are one of SCONUL's key services to its members, and the Working Group on Performance Improvement, which oversees them, will continue to develop the collection, analysis and dissemination of the data for the benefit of the sector. 